\title{
Independencia, nación y nacionalismo en México. Un ensayo de interpretación sobre un proceso multidimensional
}

Independência, nação e nacionalismo no México. Um ensaio de interpretação sobre um processo multidimensional

Independence, nation and nationalism in México. An essay of interpretation about a multidimensional process

JavierMoyano

\section{Resumen}

Con este ensayo nos proponemos interrelacionar dos procesos. En el primer caso nos referimos a un proceso corto, coincidente con la ruptura con el orden colonial y con la guerra de independencia. El segundo, tiene que ver con un lento, accidentado y multidimensional proceso de construcción de la nación mexicana y de emergencia del nacionalismo como ideología dominante. Este último proceso, aunque reconoce en la ruptura del orden colonial un punto de quiebre, atraviesa todo el siglo XIX y parte del XX, destacando especialmente las etapas transcurridas entre la derrota de la invasión francesa y la revolución mexicana, y el período de construcción de un estado postrevolucionario durante las décadas de 1920 y 1930.

Palabras clave: Independencia. México. Nación.
En marzo de 2001 los zapatistas congregaron, en el acto de culminación de una prolongada marcha por ciudades y pueblos mexicanos, a cientos de miles de personas en el zócalo principal de la capital del país. El objetivo expreso de la marcha zapatista era la conquista de un conjunto de reivindicaciones de los pueblos originarios. Secularmente avasallados por una estructura de dominación que, de modo creciente, desestructuraba sus formas de vida, para los pueblos originarios el lento y trabajoso proceso de construcción de una nación y un estado habían profundizado aquella situación. Ello era

\footnotetext{
Doctor en Historia por el Colegio de México. Docente e investigador de la Universidad Nacional de Córdoba (Argentina).
}

Recebido em: 24/09/2012 Aprovado em: 14/02/2013 http://dx.doi.org/10.5335/hdtv.13n.1.3001 
así porque el proceso unificador había sido dirigido por élites que, en función de sus propios intereses y programas, avanzaban sobre la propiedad comunitaria al mismo tiempo en que imponían un relato dominante en el cual lo indígena quedaba reducido al pasado como un ornamento para la naciente identidad mexicana.

Ahora bien, en 2001 el discurso zapatista se dirigía a dos destinatarios principales. En primer lugar, a la "sociedad civil internacional" como un interlocutor positivo para las demandas. En segundo lugar, a los mexicanos, colectivo del que, desde su propia perspectiva, las comunidades zapatistas formaban parte plenamente. No había, en cambio, alusiones a América Latina pese a la común situación de los pueblos originarios del continente, tanto respecto al pasado colonial como en relación con los agravios sufridos durante los dos últimos siglos.

Si admitimos que el proceso de construcción de la nación mexicana, al compás de la inserción en el mundo capitalista y del encumbramiento de una clase dirigente beneficiaria de esa integración, se encuentra en clara tensión con los intereses y expectativas de las comunidades originarias, cabe preguntar donde radica la fortaleza de aquel proceso, al punto de que, en la propia lucha por el respeto a la diferencia y al modo de vida de tales comunidades, una parte importante de la disputa pasa por la apropiación y el dotar de un significado distinto a una simbología nacional compartida con el antagonista. Reflexionar sobre esta cuestión ha sido la principal motivación de este ensayo.

En función de ese cometido nos proponemos interrelacionar dos procesos. En el primer caso nos referimos a un proceso corto, coincidente con la ruptura con el orden colonial y con la guerra de independencia. El segundo, tiene que ver con un lento, accidentado y multidimensional proceso de construcción de la nación mexicana y de emergencia del nacionalismo como ideología dominante. Este último proceso, aunque reconoce en la ruptura del orden colonial un punto de quiebre, atraviesa todo el siglo XIX y parte del XX, destacando especialmente las etapas transcurridas entre la derrota de la invasión francesa y la revolución mexicana, y el período de construcción de un estado postrevolucionario durante las décadas de 1920 y 1930.

El análisis de la independencia mexicana requiere, en primer lugar, reconocer que ésta es producto de un proceso de transición experimentado por el mundo novohispano tardío, a la vez que origen de una nueva transición, para nada lineal, desde la condición colonial hacia la construcción de una nación políticamente independiente. También es necesario distinguir los efectos específicos de la ruptura del orden colonial y las consecuencias de la propia dinámica de la guerra revolucionaria. Es preciso, asimismo, visualizar la incidencia que sobre los procesos posteriores tuvo el tipo social de los sujetos implicados en las guerras de independencia.

El estudio del proceso de formación nacional durante el siglo XIX, en tanto, requiere contemplar múltiples dimensiones. En primer lugar, la emergencia de una nación guarda relación con la configuración definitiva de un territorio $\mathrm{y}$, articulado con ello, con la construcción de un mercado ca- 
pitalista. En segundo lugar, se trata de un proceso en interacción con el establecimiento de instancias estatales, tanto en lo relativo a la sanción de una normativa uniforme para todos los habitantes de un territorio, como en lo referente a la capacidad infraestructural de hacer cumplir esa normativa y de generar condiciones favorables para el desarrollo capitalista. En tercer lugar, estos recorridos se encuentran interrelacionados con la constitución de grupos dominantes en condiciones de dirigir el proceso a escala nacional. En cuarto lugar, dado que la ruptura con el orden colonial encontró su legitimidad en los principios de soberanía popular y representación política, la construcción de una nación guarda estrecha relación con el problema del desenvolvimiento de la ciudadanía. Finalmente, en tanto el sentimiento de pertenencia es un rasgo decisivo, la creación y asimilación de símbolos y valores compartidos es imprescindible para estos procesos.

Hablar de transiciones previas a la independencia en el mundo novohispano requiere reconocer, en primer lugar, que se trataba de la colonia española más rica del continente. Esa condición había permitido la emergencia de poderosos grupos coloniales, agrupados principalmente en torno al ayuntamiento y al consulado de la ciudad de México. Contra ese poder se orientaron las iniciativas de la corona, y de sus funcionarios más celosos, en las últimas décadas del siglo XVIII. Esta acción, sin embargo, no se basó en la supresión de privilegios sino en la multiplicación de sus beneficios, diversificando la existencia de instituciones de antiguo régimen, en especial mediante la autorización de nuevos consulados como el de Guadala- jara y, sobre todo, el de Veracruz. En el mundo de los grupos subalternos, en tanto, una mayor presencia de la administración colonial, tanto en lo relativo a presiones fiscales como al control de los espacios de sociabilidad popular, acentuaba seculares tensiones de la sociedad novohispana. Es posible apreciar que el telón de fondo de los acontecimientos que siguieron a la destitución de Fernando VII era una sociedad colonial atravesada por tensiones, tanto entre los grupos de poder y elementos subalternos, como al interior del mundo de las élites. Ese telón de fondo contribuye a explicar, en ese contexto, la destitución de un virrey por parte de camarillas de peninsulares en 1808, así como, principalmente, una rebelión independentista, en 1810, con masivo protagonismo popular bajo la dirección de un religioso con funciones en áreas rurales y, a partir de esa experiencia, sumamente crítico de las instituciones borbónicas.

La peculiaridad de constituir la única experiencia hispanoamericana en que el movimiento independentista tuvo, en un primer momento, características masivas y populares, no sólo permite entender las causas de la derrota de este primer movimiento, sino también las consecuencias en lo relativo a un retraso de la independencia y, en relación con ello, al influjo posterior ejercido por el mantenimiento momentáneo del lazo colonial en un momento en que, en la península, el constitucionalismo estaba cuestionando el poder absoluto de la monarquía. Si bien en todo Hispanoamérica la soberanía popular fue el elemento legitimador de los gobiernos independientes, sólo en México las masas campesinas representaron, en un primer 
momento, una amenaza de que el control del proceso pudiera escapar de las manos de las élites criollas. Ello explica el compromiso de los criollos con el mantenimiento de la dominación colonial ante los movimientos de Hidalgo primero y de Morelos luego. Aunque no hay acuerdo en la historiografía sobre los factores que en 1821 condujeron a esos mismos criollos a romper el vínculo con la península, es claro que ello ocurrió tras la retracción del movimiento popular. Aunque involucraron masas en posiciones subordinadas, a partir de ese momento las disputas políticas por la dirección del proceso quedarían por mucho tiempo restringidas al exclusivo ámbito de lo notabiliar. Una vez resueltas estas disputas, en las últimas décadas del siglo XIX serían las élites notabiliares quienes liderarían la construcción de la nación mexicana.

Otra marca de la década de 1810 fue la incidencia de las cortes de Cádiz sobre los ordenamientos institucionales posteriores, dado que el vínculo colonial se rompió definitivamente en 1821. Entre otros aspectos relevantes, fue significativa la incidencia de la normativa gaditana sobre el ordenamiento municipal, en especial sobre dos aspectos principales. Por un lado, sobre la multiplicación de ayuntamientos electivos que, sumamente celosos de su autonomía, contribuyeron a una extrema fragmentación del espacio mexicano posterior a la independencia ${ }^{1}$. Por otro lado y en sentido contrario al anterior, a partir de la figura del prefecto como agente centralizador. Si asumimos que los ayuntamientos mexicanos, herederos de una antigua tradición colonial de representación de derechos ante las instancias supe- riores de la administración pero potenciados y multiplicados por la legislación gaditana, a menudo eran portadores de demandas de los pueblos, por lo general en torno a la tierra, el agua y otros recursos, demandas difícilmente integrables para los ordenamientos que las élites pretendían instaurar, podemos entender que el cercenamiento de su autonomía contribuía al bloqueo de tales demandas. Se potenciaban de este modo las tensiones entre las élites y los pueblos, quienes, excluidos de posiciones protagónicas en el proceso de construcción nacional, resistían la ofensiva de los grupos de poder. Estas tensiones se agravarían cuando, en la segunda mitad del siglo XIX, las oportunidades derivadas de la inserción en los mercados mundiales, condujeran a los grandes hacendados a avanzar sobre los recursos de pueblos y comunidades.

Otras consecuencias interrelacionadas de la guerra de independencia y de las luchas intestinas que la sucedieron fueron, al igual que en otras áreas latinoamericanas, la destrucción de riqueza y las dificultades para la desmovilización de las tropas. Mientras lo segundo, sin constituir necesariamente un factor determinante, alimentaba los conflictos interiores, lo primero constituía una clara limitación para que los sucesivos gobiernos pudieran resolver exitosamente tales desafíos. Todo ello tenía lugar, además, en un momento en que las posibilidades de inserción de la economía mexicana en el mundo no tenían aun la significación que alcanzarían varias décadas más tarde.

Señalábamos anteriormente que el proceso de independencia es producto de una transición del orden colonial tardío y, 
a la vez, origen de un proceso de transición hacia la construcción de la moderna nación mexicana. Corresponde entonces, a la luz de las observaciones precedentes, analizar las principales características de este segundo proceso.

La caída de la efímera experiencia imperial vivida por México tras la independencia ponía de manifiesto, además del carácter quimérico de las pretensiones de alcanzar tempranamente un orden estable en sustitución del orden colonial, otro conjunto de dificultades. El contexto internacional no era aun un estímulo para la actividad economica, mientras la minería, base de la economía colonial, entraba en una fase de retracción. En ese contexto, todas las inversiones europeas orientadas a la reactivación del sector terminaron en fracaso durante la primera mitad del siglo XIX.

Las permanentes luchas civiles, tanto por proyectos e intereses estructurales encontrados como por cuestiones meramente facciosas y particularistas, no sólo conspiraban contra la posibilidad de los gobiernos de estabilizarse en el poder. También eran perjudiciales para las propias perspectivas de alcanzar una configuración territorial definitiva, situación agravada por la inexistencia de un espacio económico común. Ni la delimitación territorial de Nueva España ni el área de influencia del emergente gobierno independiente estaban definidos con precisión en el momento en que se produjo la ruptura del pacto colonial. ${ }^{2}$ Con posterioridad, además de la renuncia a las pretensiones soberanas sobre el extremo norte en la guerra con Estados Unidos, país que aventajaba largamente a México tanto en materia de desarrollo económico como en lo relativo a la organización de instancias estatales y a la consecución de un orden político estable, en otras regiones tampoco estaba clara una pertenencia permanente a una unidad común. Centroamérica, que se había unido al ensayo imperial de Iturbide, se separó de México tras el fracaso de esa experiencia con la excepción de Chiapas, mientras que Yucatán, escasamente comunicada con otras regiones mexicanas, tuvo un breve período de independencia en la década de 1840.

El poder de la Iglesia católica constituía otro fuerte condicionante para las posibilidades de fortalecimiento de las incipientes instancias gubernamentales. Además de encontrar en los conservadores un firme aliado en las disputas por la dirección del proceso, y del ascendiente que ejercía sobre amplias masas populares, la Iglesia disponía de otros vigorosos recursos. Entre ellos destacaba la condición de principal propietaria territorial de bienes que no podían ser enajenados. La propiedad de la tierra interactuaba, en tanto, con la condición, detentada por la Iglesia, de principal entidad financiera mexicana. El formidable poderío económico derivado de esa doble condición encontraba un complemento en la existencia de fueros propios, con los cuales los eclesiásticos eran inmunes a cualquier injerencia del poder civil. Todo ello convertía a la Iglesia en un agente mucho más poderoso que los débiles gobiernos mexicanos y, por lo tanto, la constituía en una traba a las posibilidades de desarrollo de instancias estatales en condiciones de ejercer su autoridad en el conjunto de un territorio. ${ }^{3}$ 
Debilidad económica por la retracción de la economía y por la ausencia de suficientes estímulos en el mercado mundial; inestabilidad política por la existencia de proyectos e intereses en disputa, y por el peso del faccionalismo; configuración territorial inconclusa como consecuencia de la debilidad de las instancias estatales y de la ausencia de un mercado nacional; presencia de actores privilegiados con mayor poder que muchos gobiernos; fueron algunos de los rasgos característicos que, durante la primera mitad del siglo XIX, constituían limitaciones para alcanzar un proceso medianamente exitoso de construcción nacional. Cabe preguntar cuándo y cómo comenzaron a modificarse estos factores.

La demanda mundial de productos primarios se expandió considerablemente durante la segunda mitad del siglo XIX. La resultante reconfiguración del espacio económico mexicano reviste una particularidad respecto al resto de los países latinoamericanos. Ello se debía a que, además de los polos derivados de la expansión del comercio ultramarino, la vecindad con Estados Unidos, uno de los principales países industriales en esa etapa, implicó que junto a aquellos, otros polos económicos se orientaran hacia la frontera norte.

Para que estas oportunidades fueran efectivamente aprovechadas era preciso afrontar otros problemas. La victoria liberal en las guerras de reforma en la década de 1850, y la derrota de la invasión francesa en la década siguiente, permitieron, a un mismo tiempo, acotar el poder de la Iglesia; derribar muchas de las trabas precapitalistas que atentaban contra el desarrollo económi- co y contra la articulación de un mercado; y atenuar el peso de los conflictos políticos internos al relegar durante décadas al ostracismo a los conservadores por su colaboración con los invasores. Si bien a la victoria contra los franceses le siguió la lucha entre los vencedores, desde mediados de la década de 1870, el encumbramiento de Porfirio Díaz como presidente mexicano permitió alcanzar una prolongada estabilidad. De la mano de esta estabilidad, obtenida y preservada con métodos autoritarios, fue posible alcanzar significativos logros en materia de organización de instancias estatales, crecimiento económico, y unificación de un mercado interno con la consiguiente articulación de un espacio territorial común. La identificación, en el discurso oficial, entre el régimen político y los intereses de la emergente nación mexicana, contribuyó a la creación de símbolos y valores que pretendían apuntalar un proceso de construcción de identidades compartidas.

Se trataba, sin embargo, de un orden oligárquico que, lejos de integrar intereses de heterogéneos grupos sociales y regionales, no sólo no era capaz de hacer frente a la considerable fragmentación de la sociedad mexicana, sino que su programática política contribuía a la desestructuración de muchas comunidades y pueblos. La revolución mexicana puso en evidencia la existencia de una miríada de grupos que, aunque unidos en la impugnación al porfiriato, estaban animados por una enorme diversidad de demandas, cuyo común denominador era la resistencia a algunos de los efectos más dramáticos del proceso unificador emprendido desde el control del estado por un go- 
bierno autoritario, en especial en lo relativo a la preservación de antiguos modos de vida y del control de los recursos que hacían posible esa preservación. Se manifestaba, de este modo, que la construcción de una nación dirigida por las élites porfirianas distaba mucho aun de constituir un proyecto compartido e internalizado por amplias capas de la sociedad.

Fueron, en cambio, los responsables de la construcción del estado postrevolucionario, en las décadas de 1920 y 1930, quienes iniciaron un proceso mucho más ambicioso de unificación identitaria de una nación. Ello fue posible mediante varias vías complementarias. En primer lugar, la construcción discursiva de un adversario a través de las políticas petroleras. En segundo lugar, la efectiva integración de intereses que permitió la cooptación, por parte de partidos gobernantes que se identificaban con el estado, de dirigentes con ascendiente sobre las masas tanto entre los obreros como entre los campesinos.

En tercer lugar, las políticas educativas que penetraron las áreas más inaccesibles del territorio con maestros y "misioneros culturales". Los maestros no sólo enseñaban sus disciplinas sino que organizaban a la población en torno a diversas actividades, y muchas veces confrontaban con los adversarios de la nueva situación, fueran éstos terratenientes, sacerdotes católicos o antiguos caciques. Tales políticas contribuyeron, además, a la propagación de ideologías nacionalistas con las cuales el régimen se identificó durante años, y a la construcción definitiva de un panteón nacional que incluía, junto a los héroes de la independencia, las guerras de reforma y la revolución, a exponentes del pasado indígena, e incluso a la virgen de Guadalupe en una disputa con la Iglesia por la asignación de significado a fenómenos religiosos internalizados por la población.

El conjunto de los grupos subordinados, y especialmente las comunidades originarias, aún estaban lejos de alcanzar una plena inclusión en el orden nacional emergente de la revolución. La fragmentación de la sociedad mexicana, en tanto, se prolonga hasta nuestros días, en especial con la existencia de decenas de grupos étnicos hacia los cuales no se han elaborado políticas de integración con respeto de la diferencia. Sin embargo, la penetración del estado postrevolucionaio, culminación de un lento proceso de construcción nacional iniciado con la independencia, ha sido, es posible, suficientemente vigorosa como para que la demanda de los pueblos originarios pase, mucho mas que por el separatismo, por la inclusión y por el reconocimiento de su diversidad. En ese contexto, la disputa por otorgar un significado diferente a una simbología nacional comúnmente aceptada es parte de la lucha.

\section{Resumo}

Com este ensaio nos propomos a inter-relacionar dois processos. Em primeiro caso nos referimos a um processo curto, coincidente com a ruptura com a ordem colonial e com a guerra de independência. O segundo, relacionado a um lento, acidentado e multidimensional processo de construção da nação mexicana e da emergência do nacionalismo como ideologia dominante. Este último processo, ainda que reconheça na ruptura da ordem colonial um ponto de ruptura, 
atravessa todo o século XIX e parte do $\mathrm{XX}$, destacando especialmente as etapas transcorridas entre a derrota da invasão francesa e a revolução mexicana, e o período de construção de um estado pós-revolucionário durante as décadas de 1920 e 1930.

Palavras-chave: Independência. México. Nação.

\section{Abstrat}

In this paper we inter relate two processes. In the first case we refer to a short process, coincident with the break with the colonial order and the war of independence. The second has to do with a slow, bumpy and multidimensional process of nation building and emergency Mexican nationalism as the dominant ideology. The latter process, while recognizing in the breakdown of the colonial order a breaking point, traverses the nineteenth and twentieth part, especially highlighting the steps elapsed between the defeat of the French invasion and the Mexican Revolution, and the construction period of the postrevolutionary state during the 1920s and 1930s.

Keywords: Independence. Mexico. Nation.

\section{Notas}

1 Annino, Antonio, “Cádiz y la revolución territorial de los pueblos mexicanos 1812-1821", en Annino, Antonio, Historia de las elecciones en Iberoamérica, Siglo XIX, México, Fondo de Cultura Económica, 1995, p. 177-179.

2 Ávila, Alfredo, "México: un viejo nombre para una nueva nación", en Chiaramonte, Juan Carlos, Marichal, Carlos y Granados, Aimer, Crear la nación. Los nombres de los países de América Latina, Buenos Aires, Sudamericana, 2008, p. 273-276.
3 San Juan Victoria, Carlos y Velázquez Ramírez, Salvador, "La formación del Estado y las políticas económicas (1821-1880)", en Cardozo, Ciro, Coordinador, México en el siglo XIX (1821-1910). Historia económica y de la estructura social, México, Nueva Imagen, 1992, p. 80.

\section{Bibliografía}

ANNINO, Antonio. Cádiz y la revolución territorial de los pueblos mexicanos 1812-1821, en ANNINO, Antonio. Historia de las elecciones en Iberoamérica, Siglo XIX, México, Fondo de Cultura Económica, 1995, p. 177-226.

ÁVILA, Alfredo. México: un viejo nombre para una nueva nación, en CHIARAMONTE, Juan Carlos; MARICHAL, Carlos; GRANADOS, Aimer. Crear la nación. Los nombres de los países de América Latina. Buenos Aires: Sudamericana, 2008, p. 271-284.

CHIARAMONTE, José Carlos. Nación y Estado en Iberoamérica. El lenguaje político en tiempos de las independencias. Buenos Aires: Sudamericana, 2004.

GUERRA, Francois-Xavier. Modernidad e independencias. Ensayos sobre las revoluciones hispánicas. México: Fondo de Cultura Económica, 2001.

LA GARZA, Luis. El México postindependiente. En: Evolución del Estado mexicano. México: Ediciones El Caballito, 1986, p. 21-84.

LOYO, Engracia. Gobiernos revolucionarios y educación popular en México. México: El Colegio de México, 1999.

MEYER, Lorenzo. El Primer tramo del camino. En: Historia General de México, v. II. México: El Colegio de México, 1999.

SOLER, Ricaute. Idea y cuestión nacional latinoamericanas. De la independencia a la emergencia del imperialismo. México: Siglo XXI Editores, 1987.

San Juan Victoria, Carlos y Velázquez Ramírez, Salvador, "La formación del Estado y las políticas económicas (1821-1880)", en Cardozo, Ciro, Coordinador, México en el siglo XIX (1821-1910). Historia económica y de la estructura social, México, Nueva Imagen, 1992, p. 65-87. 